\title{
A Diagnostic Application of HEC- HMS Model to Evaluate the Potential for Water Management in the Ratnapura Watershed of Kalu Ganga Sri Lanka
}

\author{
P.M. Jayadeera and N.T.S. Wijesekera
}

\begin{abstract}
Practicing water managers and engineers require watershed models that could be applied with confidence. This requires already calibrated and verified mathematical watershed models with transparent and rational guidance on the selection of model components representing watershed processes, identification of the objective function, evaluation criteria, data and data resolution etc. This work demonstrates the diagnostic development of a popular and free HEC HMS model for Ratnapura watershed $\left(635 \mathrm{~km}^{2}\right)$ while evaluating the potential for water management with respect to floods, water resources and dry weather flows, using rainfall of four stations, evaporation at one station and streamflow corresponding to the period from 2006-2014. Activities, such as model development, parameter optimisation, evaluation etc., were determined after a rational evaluation. Flood peak magnitude and time of occurrence matched well while water yield estimation, except for questionable data periods, was very good. This reflects that the developed HEC- HMS model with its optimised parameters can be used for flood management with confidence. Most critical flow components for water resources management showed a very good agreement between the observed and modelled streamflow values. High errors in low flow estimation indicated that this model cannot be recommended for environmental flow management.
\end{abstract}

Keywords: Hydrologic modelling, HEC-HMS model, Model calibration \& Model verification

\section{Introduction}

Hydrological models are important for a wide range of applications, including water resources planning, development and management, flood prediction and design, and modelling of coupled systems including water quality, hydro-ecology and climate (Pechlivanidis et al. [16]). Mathematical models for watershed management has a history of about 50 years and presently they have advanced to detailed and extensive mathematical representations of watershed hydrology coupled with remote sensing with Geographic Information Systems. However, a recent review of World Banksupported projects that aim to address watershed management problems indicated that modelling and other related tools have so far been applied only to a limited extent (Lund et al. [11]). Development of watershed models remains a high level approach requiring sufficient knowledge on modelling, parameter optimization, model calibration and verification etc., (Hearn [9]). Practical use of watershed models for engineering and management of a particular watershed requires guidelines accepted by policymakers recommending details and parameters for model development. Other than for models such as Unit
Hydrograph or the SCS curve number for streamflow estimation, there is a lack of guideline parameters for the development of modelling systems such as HEC HMS. In case of Kalu Ganga basin of Sri Lanka, there had been many occasions where several models had been applied and reported (Wijesekera and Musiake [25]), (Kanchanamala et al. [10], (Nandalal and Ratnayake [15]). However, it appears that a diagnostic model development with sufficient details is required to build up the confidence of watershed managers to develop their own models using the reported information. In case of Sri Lanka, reported mathematical modelling work for watersheds is limited (Wijesekera [24]).

Eng. P.M. Jayadeera, C.Eng., MIE(SL), B.Sc. Eng. (Hons) (Moratuwa), M.Eng. (Moratuwa), Director of Irrigation (Colombo Region), Irrigation Department, Sri Lanka. Email:priyanimjayadeera@gmail.com

ORCID ID: http://orcid.org/0000-0003-1183-8995

Eng. (Prof.) N.T.S. Wijesekera, C.Eng., MIECE (UK), FIE(SL), B.Sc. Eng.Hons (Peradeniya), PG Dip(Moratuwa), M.Eng. (Tokyo), Ph.D(Tokyo), Senior Professor,

Department of Civil Engineering, University of Moratuwa, Sri Lanka.

Email:sohanw2@gmail.com

ORCID ID: http://orcid.org/0000-0003-0964-4331 
Continuous hydrologic modelling synthesizes hydrologic processes and phenomena over a longer time period, which includes both wet and dry conditions (Xuefeng and Steinman [29]). Continuous models enable a manager to select and manage water during high, medium and low flow periods. Therefore, the overall objective of the present work is to carry out a diagnostic development of a popular and free watershed model while evaluating the potential for water management with respect to floods, water resources and low flows.

HEC HMS is a free watershed model widely applied in the world and to a certain extent in Sri Lanka too. In case of Sri Lankan case studies, it has been identified that the Snyders UH transform method and deficit constant loss method proved to be good options when modelling Attanagalu Oya watershed (Halwatura and Najim [8]). HEC HMS model performance as a distributed model in the Ratnapura watershed has been reported (Kanchanamala et al. [10]). After an evaluation of the advantages and the reported experiences, the present work carried out a diagnostic HEC HMS model development for the Kalu Ganga watershed of Sri Lanka.

\section{Study Area}

Kalu Ganga is the third longest river in Sri Lanka, originating from Adam's Peak and discharging the largest amount of water into the ocean while causing floods along its route, starting from the upstream major town Ratnapura to the most downstream town, Kalutara.

This river basin in the wet zone of Sri Lanka with an area of approximately $2690 \mathrm{~km}^{2}$ has a main Kalu Ganga which is 129 km long. Mountainous forests including the Sinharaja Forest Reserve are the main drainage areas. Watershed at Ratnapura (Figure 1) which has a drainage area of $635 \mathrm{~km}^{2}$ was selected for model development.

\section{Data \& Methodology}

\subsection{Data \& Data Checking}

Daily rainfall data of four rainfall stations (Ratnapura, Alupola, Pelmadulla and Nivithigala), monthly evaporation data at Ratnapura and Daily streamflow at Ratnapura, for the study period 2006-2014 were collected. Land use data $(1: 50,000)$ and $(1: 10,000)$ terrain data were from the Department of Survey. Visual data checks were performed to identify any disparities in the patterns. Monthly and annual rainfall variations of each station were plotted and compared. Moving average rainfall for all stations was plotted to check for significant variations in the annual rainfall. Double mass curves did not reflect data inconsistency. Compatibility of Thiessen average rainfall with streamflow indicated that use of December, January and February of $2007 / 2008$ water year data needs caution. The water year 2011/2012 reflected as a year with very low annual streamflow, demonstrating a very low runoff coefficient. Modelling was pursued with a note of data disparities and aiming to address with model estimations.

\subsection{Model Development}

\subsubsection{Development of basin model}

Watershed model for Kalu Ganga at Ratnapura was developed as a single lumped model. Under this task, the selection of model components, objective function, flow thresholds for evaluation, evaluation method, calibration and verification requirements were selected with reasoning.

\subsubsection{Precipitation loss model}

The two mostly used loss models are the use of Green Ampt equation to account for infiltration and the SCS method which uses the storm rainfall (Chow et al. [3]). In the only loss rate evaluation study carried out in Sri Lanka, the average storm method had performed well with catchments receiving uniform rainfall (Manchanayake et al. [13]). In literature, median initial loss values have been reported as guidance material (El-Kafagee and Rahman [5]). Deficit constant loss method had performed better than the SCS CN loss method in case of Attanagalu Oya basin in Sri Lanka (Halwathura and Najim [8]). Amidst very limited work on loss models, the challenge for a practicing HEC HMS modeller is the selection of a precipitation loss model. The available options in HEC HMS model are, namely Soil and Conservation Service (SCS), Green and Ampt (G.A.), Initial Constant (I.C.), Deficit Constant (D.C.), Constant Fraction (C.F.), Exponential (Exp.) and Soil Moisture Accounting (SMA). Only the D.C. method and the SMA method can be used for continuous hydrologic modelling (Cunderlik and Simonovic [4]). The SMA model has 12 parameters that may perform better in case of distributed modes (Bashar and Zaki [1]). On the other hand, the matured deficit and constant loss method is easy to setup and use, and has only three parameters, namely Initial Deficit, Maximum Storage and Constant Loss. 


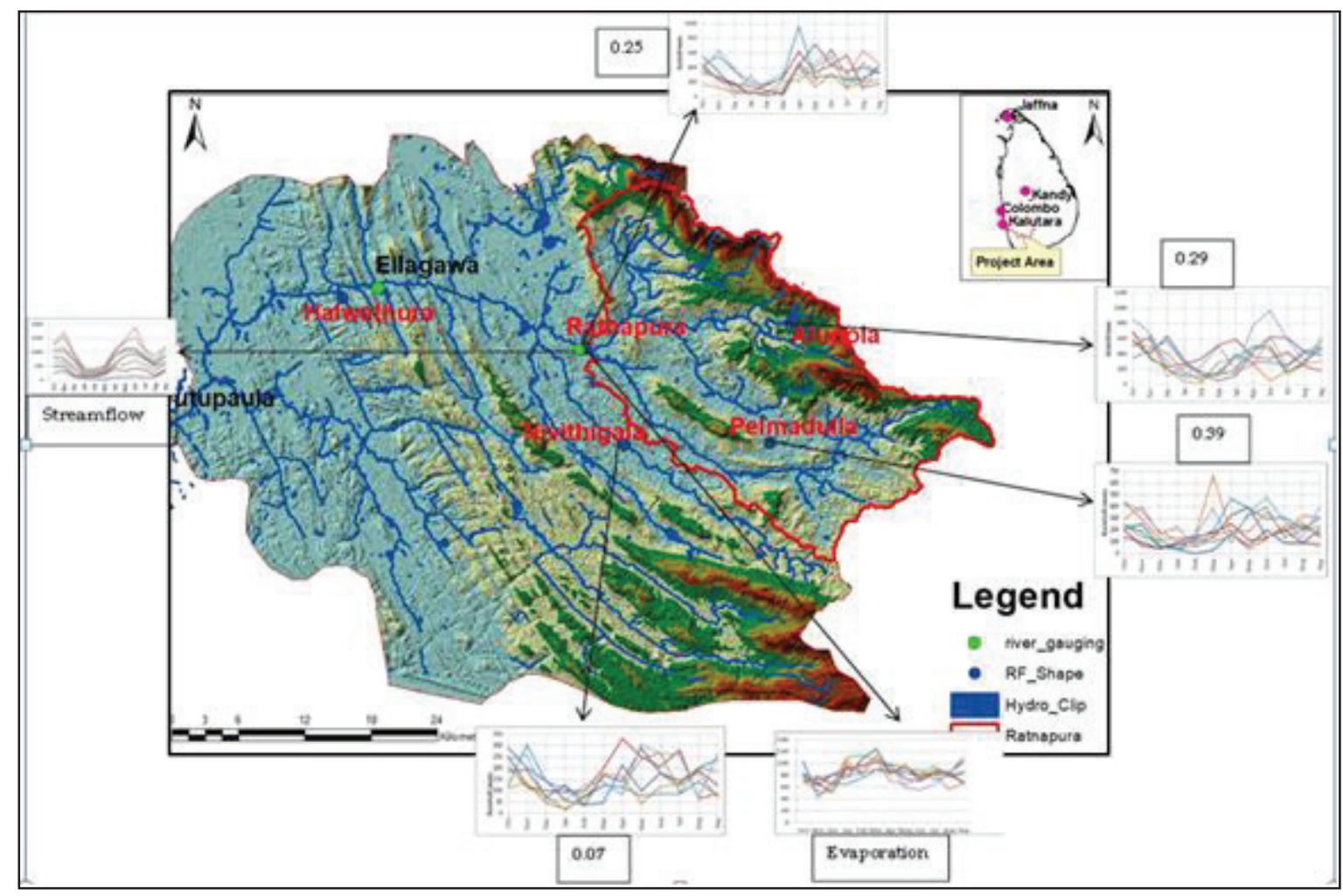

Figure 1 - Rainfall and streamflow stations, Monthly rainfall and Thiessen weights of Ratnapura Watershed

The maturity, a smaller number of parameters, consideration of soil wetness, and easy setting up were the major considerations for the selection of D.C. for the present study. According to USACE [18], initial deficit indicates the amount of water required to saturate the soil layer to the maximum storage; maximum storage is the amount of water the soil layer can hold specified as a depth. The upper bound would be the depth of active soil layer multiplied by porosity. Though there are no typical values, the maximum storage is similar to maximum potential retention $(S)$ in the SCS Curve Number method (Chow et al. [3]). Composite $\mathrm{CN}$ value for the watershed can be computed using the antecedent moisture condition, land use and soil group (USDANRCS [20]). The constant loss rate defines the infiltration rate when the soil layer is saturated (USACE [18]).

Guidance to the selection of soil group, antecedent moisture condition and maximum potential retention were obtained from Chow et al. [2]) and USDA-NRCS [20]. Chow et al. [2]) relate land use with soil groups. Accordingly, $\mathrm{CN}$ values for each land use category in Table 1 were obtained from Table 5.5.2 of Chow et al. [2]), assuming soil group $C$ for the Ratnapura watershed. These were used to compute composite $\mathrm{CN}$ values. The normal antecedent moisture condition was taken because of the regular alternating two monsoon climate and the absence of long, dry or wet periods.

Table 1 - Land Use Types of Ratnapura Catchment

\begin{tabular}{|l|r|r|}
\hline Land Use Type & Area $\left.\mathbf{( k m}^{\mathbf{2}}\right)$ & \% Area \\
\hline Forest & 122.46 & 19.3 \\
\hline Agriculture & 197.43 & 31.1 \\
\hline Homestead & 108.83 & 17.1 \\
\hline Inland water & 7.92 & 1.2 \\
\hline Other & 198.27 & 31.2 \\
\hline
\end{tabular}

\subsubsection{Transform model}

HEC HMS provides a total of seven different transform models for surface runoff computation. The options include several unit hydrograph (UH) methods, a kinematic wave method and a linear quasi distributed method. In the case of Attanagalu Oya basin in the wet zone of Sri Lanka, Snyders UH method had provided better simulations when compared 
with Clark UH method (Halwathura and Najim [8]). There are two parameters, namely time of concentration and the storage coefficient, required to use Clarks $\mathrm{UH}$ method. In case of Snyders UH method and SCS UH method, there are empirical equations that could be used for the computation of associated parameters that need to be otherwise calibrated. Though there are similarities in the SCS and Snyder's UH methods (Chow et al. [3]), the SCS method was selected because the parameters are closely linked with watershed characteristics.

\subsubsection{Baseflow model}

The HEC HMS model includes three alternative models of baseflow. They are, the constant monthly-varying value, exponential recession model and linear reservoir volume accounting model.

Recession baseflow model is designed to approximate the typical behaviour observed in watersheds when channel flow recedes exponentially after an event. Although this method is intended primarily for event simulation, it has the ability to automatically reset after each storm event, and consequently may be used for continuous simulation (USACE [18]). Hence the recession model was selected for the present study. The three parameters of recession baseflow model are: (1) Initial flow (2) Recession Constant and (3) Recession Threshold Flow/Ratio. They were determined by parameter optimization.

\subsubsection{Development of meteorologic model}

In the absence of precipitation distribution studies applicable to the watershed and considering the wide usage in continuous models, the station geometry-based Thiessen average method was selected from the seven different watershed rainfall computation options available in the HEC HMS meteorologic model. The model applied is a single lumped model and hence the canal routing component of the model does not play a role.

\subsection{Model Evaluation}

Model evaluation was carried out by considering the entire streamflow time series, high, medium, low flow regimes in the periodof-record flow duration curve (FDC) and the annual water balance during model estimations. Matching of flood peak magnitude and time of occurrence estimations is the key to evaluate the flood management capability. The overall hydrograph matching is used to demonstrate the model response to daily streamflow. FDC and water balance matching assists the identification of the goodness of model for water yield estimation (Zhang et al. [30]) \& Ward and Elliot [23]). The natural change of gradient in the period-of-record FDC indicated that the high flows in the watershed had a probability of exceedance less than $10 \%$ while the same for low flows was greater than $80 \%$.

\subsubsection{Objective function}

A review of literature presents many objective functions for a watershed modeller, based on a modelling objective which can be either flood control, water utilization or managing environment with the dry weather flow (Green and Stephenson [7]). Objective function use also differs from researcher to researcher even with the same objective (Madsen [12]), Giang and Phuong [6]), Cunderlik and Simonovic [4], World Meteorological Organization [27], Wijesekera and Musiake [25], Wu et al. [28]). There are five recommended objective function options in the HEC HMS (USACE [18]).

The Weighted Root Mean Square (WRMS) is a common choice for a minimization problem while Nash Sutcliffe or Total Runoff Volume are the common choices for a maximization problem (USACE [22]).

The Mean Ratio of Absolute Error (MRAE) (Wijesekera and Musiake [25]), which is an indicator of sum of residual error relative to the magnitude of the measured streamflow at each point of observation, the Percent Error in Volume (PEV) (Green and Stephenson [7]) closely connected with the mass balance error and Nash-Sutcliffe (NS) (Green and Stephenson [7]) which is a common choice were evaluated using a sample dataset. MRAE, which looks at relative estimation error, was taken as the principal objective function while the Nash Sutcliffe and Annual Mass Balance were observed when arriving at the best set of parameters. These functions are listed in equations 1, 2 and 3 . In these equations, the suffixes $\mathrm{O}$ and $\mathrm{C}$ stands for observed and calculated values respectively. $n$, and $V$ represent the number of data and streamflow volume.

$$
\begin{gathered}
\text { MRAE }=\frac{1}{n} \sum \frac{\left|Q_{o}-Q_{c}\right|}{Q_{o}} \\
\mathrm{NS}=1-\frac{\sum\left(Q_{o}-Q_{c}\right)^{2}}{\sum\left(Q_{o}-\overline{Q_{o}}\right)^{2}} \\
P E V=\frac{V_{O}-V_{C}}{V_{O}} \times 100
\end{gathered}
$$


After careful consideration of work by Cunderlik and Simonovic [4] and a comparative evaluation with sample data, the univariate method of HEC HMS was selected as the search algorithm for parameter estimation while using SAR as the objective function. The parameter values optimized using this automatic optimization method were then finetuned with manual calibration using MRAE as the principal objective function. Visual observation of entire streamflow series, evaluation of flow regimes in the duration curve, NS coefficient and Annual Water Balance estimations were used to determine the appropriateness of optimized parameters.

\subsubsection{Simulation controls}

As per guidance in USACE [18], the lag time for Ratnapura basin which is 39 hrs produces a recommended simulation time interval of approximately 11 hrs. Considering the computational accuracy that could be meaningfully achieved with daily base data, a sample streamflow estimation was carried out by varying simulation time intervals. Change of simulation time interval from 6 hours to 24 hours showed that the annual mass balance would change approximately by $6 \%$ due to the shift in the estimated hydrographs. Hence a 6 hour simulation time interval was selected while taking 01 October 2006 to 30 September 2010 as the calibration period. After several cyclic model runs with the calibration dataset, it was found that a four year warm up period was sufficient to stabilize the initial soil moisture conditions. Data from 2010/2011 to 2013/2014 was used for model verification.

\section{Results}

\subsection{Watershed Status}

Study watershed experiences a two-peak rainfall from both monsoons. Average annual rainfall, streamflow and evaporation over the study period are 3164, 1634, and 1530 $\mathrm{mm}$ /year, respectively (Table 2).

Annual runoff coefficient of Ratnapura catchment varied from 0.39 to 0.66 during the 8 year period. In water years 2007/2008 and 2011/2012, watershed runoff coefficient showed a significant deviation from the average. Daily rainfall values showed that most of high spatially averaged rainfall resulted with high streamflow peaks but the dry season from January to March months revealed most of the incompatibilities. This situation, probably due to a deficiency in the rainfall spatial averaging method or due to errors in measured data, hinted the likelihood of difficulties during model development and streamflow matching during the dry season.

\subsection{Calibration and Verification}

Hydrograph matching and duration curve matching during model calibration and verification are shown in Figure 2 to 5.

Table 3 - Model Evaluation Indicators

\begin{tabular}{|l|r|r|}
\hline Indicator & Calibration & Verification \\
\hline MRAE & 0.5226 & 0.773 \\
\hline Nash Sutcliff & 0.783 & 0.585 \\
\hline MRAE High flow & 0.05 & 0.2333 \\
\hline MRAE Intermediate flows & 0.1198 & 0.316 \\
\hline MRAE Low flows & 0.6315 & 0.8315 \\
\hline
\end{tabular}

Calibration and verification results show good overall matching of entire hydrograph (Table 3). Similar performance during verification indicated the robustness of the model and the calibrated parameters. MRAE values for the high, medium and low flows during FDC matching indicated very good estimation of high and medium flows during calibration and verification. However, low flow estimations, both during calibration and verification, indicated low degree of matching with the observed values. (Table 3). Mean annual volume error estimates are in Table 4. Annual average high, medium and low flow volume errors during calibration are $38 \mathrm{MCM}, 51 \mathrm{MCM}$ \& $22 \mathrm{MCM}$, respectively. In an overall context, annual average volume error during calibration is below $2.1 \%$. The same during verification is $12.4 \%$.

Matching flood magnitude and the time of occurrence during calibration and verification indicates the strong capability to manage floods (Table 5). In this, observed flood peaks in the high flow region were identified. Matching of peaks and their occurrence was evaluated. MRAE of flood peak matching was very good with 0.47 and 0.37 during calibration and verification, respectively. The summary results in Table 5 show that the average estimation error with respect to the timing of the flood peak was approximately half a day. Since the modelling was carried out at a daily temporal resolution, the minimum actual error that can result is one day. The averaging with all flood events indicating a less than one day value shows that in most occasions there were no estimation error in the timing of flood peak. Therefore the model shows a very good matching. 
Table 2 - Annual Water Balance comparison

\begin{tabular}{|c|c|c|c|c|c|c|}
\hline & \multirow[t]{2}{*}{ Year } & \multirow{2}{*}{$\begin{array}{c}\begin{array}{l}\text { Annual RF } \\
(\mathrm{mm} / \mathrm{yr})\end{array} \\
\text { Obs }\end{array}$} & \multicolumn{2}{|c|}{ Annual SF (mm/yr) } & \multicolumn{2}{|c|}{$\begin{array}{c}\text { Annual Water } \\
\text { Balance }(\mathrm{mm} / \mathrm{yr})\end{array}$} \\
\hline & & & Obs & Est & Obs & Est \\
\hline \multirow[t]{4}{*}{ Calibration } & $2006 / 2007$ & 2634 & 1630 & 1427 & 1004 & 1208 \\
\hline & $2007 / 2008$ & 3045 & 2016 & 1995 & 1028 & 1050 \\
\hline & $2008 / 2009$ & 2918 & 1707 & 1663 & 1210 & 1255 \\
\hline & $2009 / 2010$ & 3417 & 1716 & 1842 & 1701 & 1575 \\
\hline \multirow[t]{4}{*}{ Verification } & $2010 / 2011$ & 3514 & 1854 & 1865 & 1660 & 1650 \\
\hline & $2011 / 2012$ & 2041 & 871 & 504 & 1170 & 1536 \\
\hline & $2012 / 2013$ & 4348 & 1964 & 2633 & 2385 & 1715 \\
\hline & $2013 / 2014$ & 3391 & 1311 & 1741 & 2080 & 1650 \\
\hline \multicolumn{2}{|c|}{ Average Annual } & 3164 & 1634 & 1709 & 1530 & 1455 \\
\hline
\end{tabular}

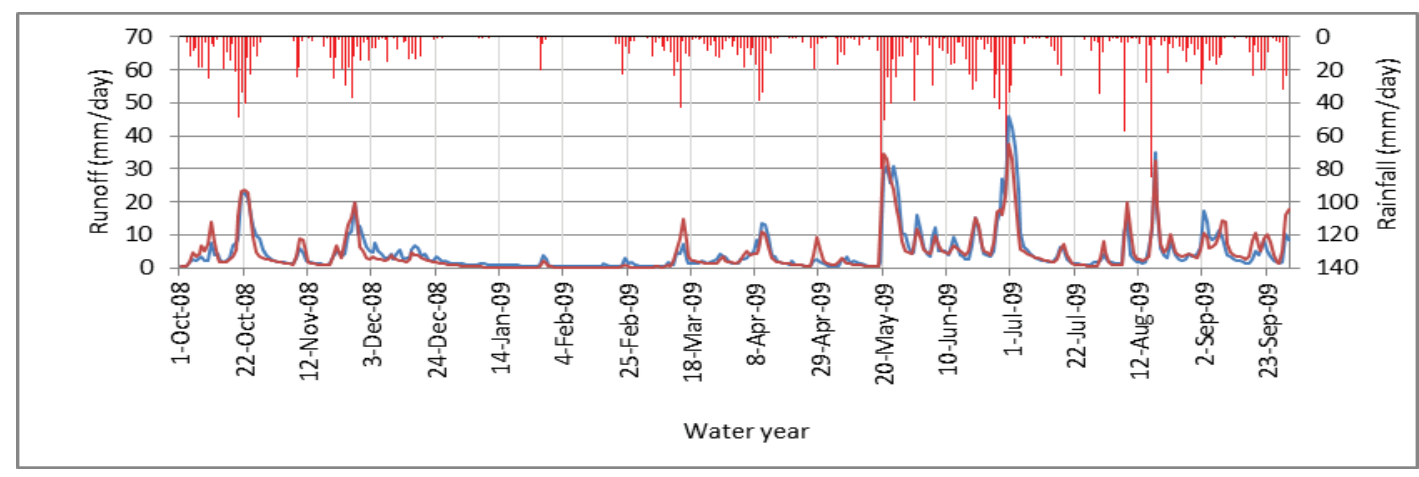

Figure 2 - Streamflow comparison (Calibration)

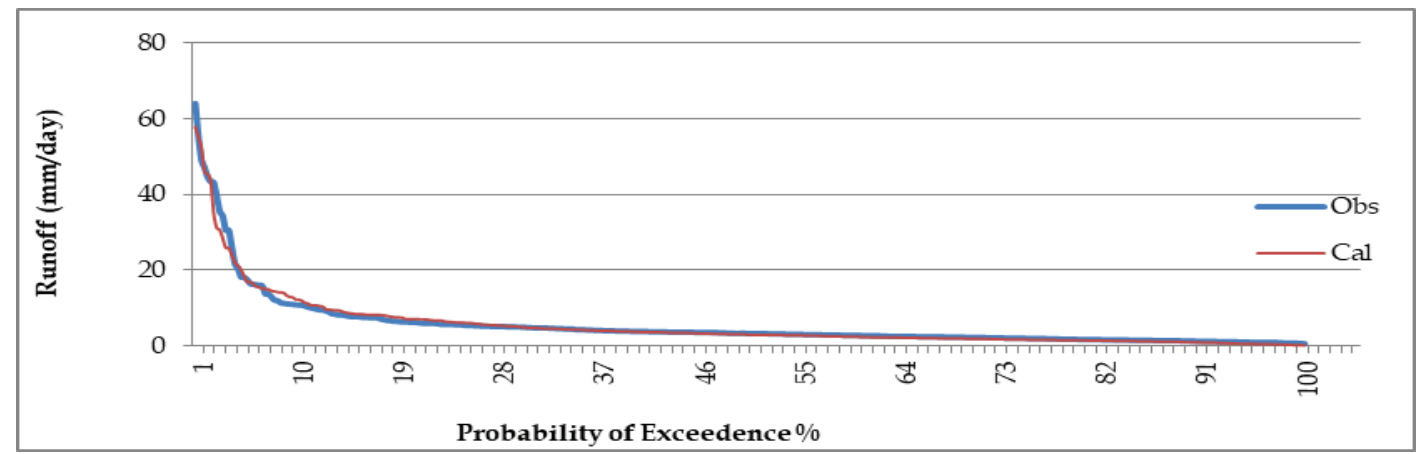

Figure 3 - Flow duration curve (Calibration) 


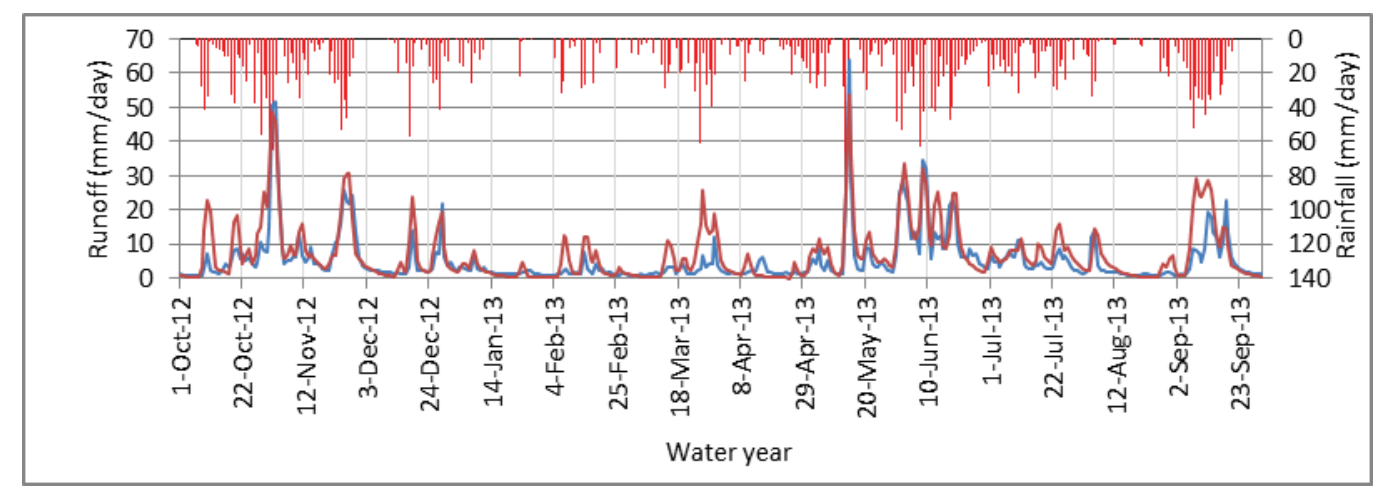

Figure 4 - Streamflow comparison (Verification)

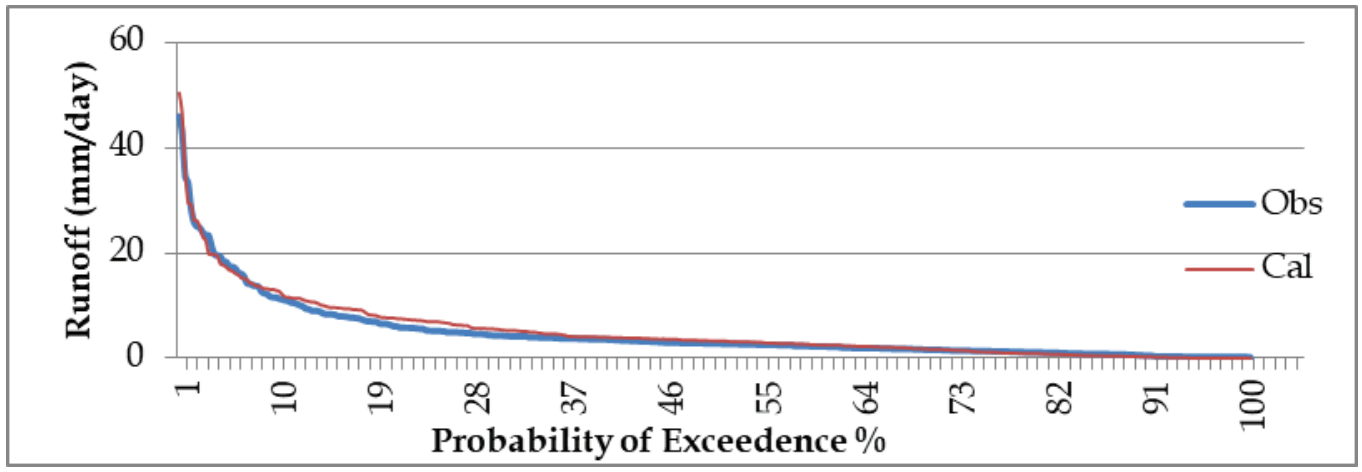

Figure 5 - Flow duration curve (Verification)

Table 4 - Average Annual Streamflow Volume Matching During Calibration and Verification

\begin{tabular}{|l|l|l|l|l|l|l|l|l|l|}
\hline & \multicolumn{4}{|c|}{ Calibration } & \multicolumn{3}{c|}{ Verification } & Both \\
\hline $\begin{array}{l}\text { Average Annual } \\
\text { Streamflow } \\
\text { (MCM/yr) }\end{array}$ & High & Medium & Low & Overall & High & Medium & Low & Overall & Overall \\
\hline $\begin{array}{l}\text { Observed Streamflow } \\
\text { Q (MCM) }\end{array}$ & 473 & 613 & 37 & 1123 & 479 & 617 & 37 & 953 & 2075 \\
\hline $\begin{array}{l}\text { Calculated } \\
\text { Streamflow Q (MCM) }\end{array}$ & 435 & 619 & 28 & 1099 & 452 & 622 & 19 & 1070 & 2170 \\
\hline $\begin{array}{l}\text { Error in Estimation } \\
\text { (MCM) }\end{array}$ & 38 & 51 & 22 & 23 & 28 & 50 & 18 & 118 & 95 \\
\hline \% Error in estimation & 3.4 & 4.5 & 1.9 & 2.1 & 2.5 & 4.3 & 1.6 & 12.4 & 4.6 \\
\hline
\end{tabular}

Table 5 - Evaluation of High Flow Estimation during Calibration

\begin{tabular}{|l|l|l|}
\hline \multicolumn{1}{|c|}{ Floods - Probability of Exceedance $<10 \%$} & Calibration & Verification \\
\hline No. of High Flood Peaks & 61 & 50 \\
\hline Range of Flood Peak (mm/day) & $9.03-64.12$ & $9.03-64.04$ \\
\hline MRAE for Peak flow Magnitude & 0.47 & 0.37 \\
\hline $\begin{array}{l}\text { Average Error Time of Occurrence (Deviation ) of flood peak in } \\
\text { Days }\end{array}$ & 0.37 & 0.38 \\
\hline $\begin{array}{l}\text { Mode of Error in Flood Peak Time of Occurrence (Deviation) in } \\
\text { Days }\end{array}$ & 0 & 0 \\
\hline
\end{tabular}


The high flow threshold for the selected data period is $9.03 \mathrm{~mm} /$ day. Streamflow quantities not greater than this threshold were considered as the most likely yield for water resources applications. Seasonal yield computations during calibration and verification and the RAE values are in Figure 6.

The HEC HMS model parameters were determined either using physical characteristics of the watershed or by means of calibration and verification. Thiessen values of each rainfall station are shown in Figure 1. The weighted $\mathrm{CN}$ value for the watershed was 77 . Initial abstraction value for the watershed amounted to $15.2 \mathrm{~mm}$. Four repeated data cycles revealed that a warm up period of 4 years is adequate for the determination of initial conditions. Optimised model parameters are shown in Table 6.

Table 6 - Optimized Model Parameters

\begin{tabular}{|l|c|c|c|}
\hline Parameter & Unit & $\begin{array}{l}\text { Initial } \\
\text { value }\end{array}$ & $\begin{array}{l}\text { Optimized } \\
\text { value }\end{array}$ \\
\hline $\begin{array}{l}\text { Constant } \\
\text { loss }\end{array}$ & $\mathrm{mm} / \mathrm{hr}$ & 0.5 & 0.435 \\
\hline Initial deficit & $\mathrm{mm}$ & 10 & 4.489 \\
\hline $\begin{array}{l}\text { Recession } \\
\text { constant }\end{array}$ & 0.9 & 0.896 \\
\hline $\begin{array}{l}\text { Threshold } \\
\text { flow ratio }\end{array}$ & & 0.1515 & 0.149 \\
\hline \begin{tabular}{l} 
Lag time \\
\hline
\end{tabular} & minutes & 3247 & 2127 \\
\hline
\end{tabular}

\section{Discussion}

\subsection{Flood Management}

Overall MRAE values of 0.5226 and 0.773 for model calibration and verification reflect satisfactory overall model performance during model calibration. Estimation of high and medium streamflow demonstrates a very good matching while the poor low flow estimation had resulted in demonstrating poor model performance indicators.

It was observed in Table 5 that, in case of floods, up to $10 \%$ of probability of occurrence, average flood peak estimation matching was very good during calibration and verification with respective MRAE values of 0.47 and 0.37 . Average error of time of occurrence of flood peak during both calibration and verification was approximately half a day. The mode of the time differences showed that the time of occurrence estimation error was zero days. This reflects that the developed HEC HMS model with its optimised parameters would enable flood management with confidence.

\subsection{Water Resources Management}

Model estimation of high and intermediate flows are the most critical for the estimation of streamflow that can be harnessed for water use. Behaviour of the most critical flow components for water resources management show a very good agreement between the observed and modelled streamflow values. Comparison of observed and modelled streamflow values that can be harnessed as water resources were compared on a seasonal basis. Seasonal watershed yield values show that matching during calibration and verification periods is very good except for the 2011/2012 and $2012 / 2013$ water years. In the other periods, comparison of estimations for both Yala and Maha seasons show very good RAE values below 0.30 (Figure 6).

\subsection{Management of Low Flows}

Low flow threshold corresponding to the $80 \%$ exceedance probability for the study period is $1.29 \mathrm{~mm} /$ day. Low flow estimation errors in the model reflected a poor matching. Poor low flow estimation errors are most likely due to the quality of low flow measurements. It is likely that the model optimisation was not sufficiently facilitated due to this reason. For example, the incompatibility of rainfall and low flows during February \& March in 2009, January \& February in 2013 etc., indicates the difficulty for the model to show a good response. Therefore, input data measurements must be carefully monitored and quality must be ensured for further investigation of low flow estimations. Semi logarithmic plots of observed and computed streamflow hydrographs and flow duration curves also indicated a significant deviation in the daily values. MRAE values of 0.6315 and 0.8315 , during calibration and verification respectively, clearly indicated that the use of model for low flow pattern management in a daily time scale cannot be endorsed. However, a comparison of the flow quantities in Table 4 demonstrates a small order of magnitude error with respect to the estimation of high or intermediate flows during calibration and verification. 


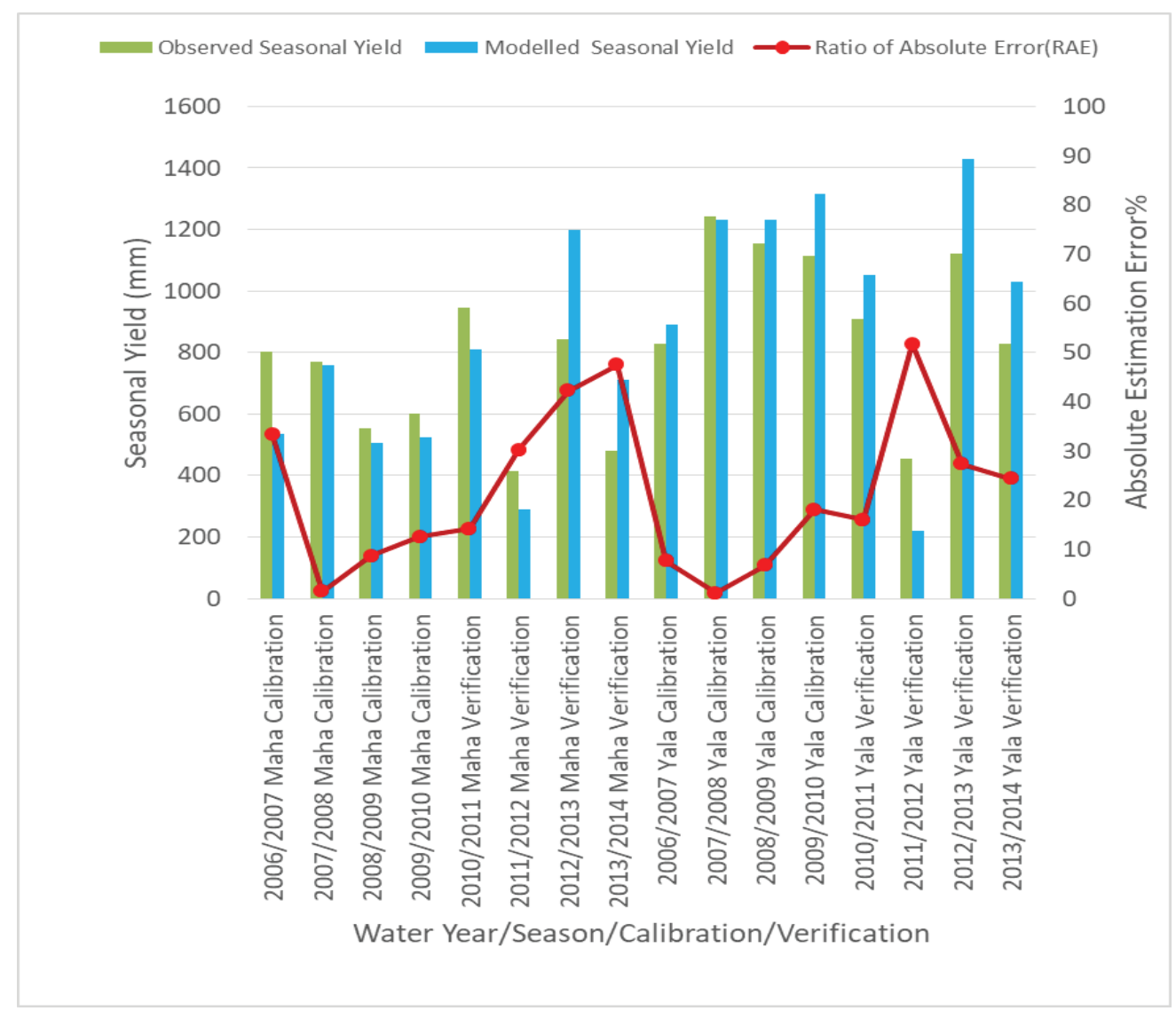

Figure 6 - Seasonal yield computations during calibration \& verification

\subsection{Model Evaluation and Data Issues}

Use of MRAE as the objective function, comparison of streamflow hydrographs and FDC curves enabled the identification of optimum model parameters. Streamflow estimates, in the range $10 \%$ to $80 \%$ probability of exceedance, showed several unrealistic over predictions. This could be either due to errors in base data or due to method of rainfall averaging.

If these points are avoided, a better fitting could be expected and the results would improve further. Evaluation of flood peaks reflected that the model did not respond to some of the observed flood events. Comparative watershed yield estimations also showed periods of higher disparity.

High errors in low flow estimations prompt the need to pay attention to the low flow data measurement and recording. Data checking revealed incompatibilities in the Thiessen averaged rainfall and observed streamflow, and they most likely caused an impact in the optimization results, especially in the low flow periods. Therefore, in future modelling, better attention must be paid to the rainfall averaging methods, representativeness of rainfall measurements used for the model, and also to the acquisition of better quality data.

Unrealistic catchment responses, either by means of streamflow data errors or due to rainfall data inadequacies, cause problems during parameter optimization. In these situations, it is important to carryout systematic and careful model evaluations. These issues may be either because of data errors or due to the model attempting to provide average parameters that could represent the watershed heterogeneity.

\subsection{Model Development}

Model development was based on the selection of conceptual models for each process and the determination of best parameters, either from physical characteristics, empirical relationships or by optimization. These and many other assumptions, such as soil group, hydrological condition and land use classification, can lead to model parameter selection issues. 
This study selected the model components after a critical comparative evaluation. Then, results were evaluated using numerous water use based criteria. Appropriate objective function selection, prudent data checking and selection of two, four year data periods for calibration and verification, are some of the strengths in the model development. This type of transparent and descripting modelling is expected to lead the other ongoing modelling efforts towards meaningful results.

\section{Conclusions}

1. A HEC HMS model was systematically developed for Kalu Ganga basin at Ratnapura with an acceptable level of accuracy showing a MRAE of 0.5226 during calibration. MRAE value during verification was 0.773 .

2. Model is capable of flood management with a very high level of accuracy in the daily time scale.

3. The high ability to estimate watershed yield in the Yala and Maha seasons demonstrates the Water Resources Management capability of the Model.

4. High low flow estimation errors show that the model cannot be recommended for environmental flow management at daily time scale.

5. Evaluated Model component selection and judicial selection of objective function and evaluation criteria are very important for the development of a watershed model.

6. Diagnostic model selection, development and evaluation are important components of streamflow modelling for water management

\section{Acknowledgement}

Support received by the contributions of Late Shri Madanjeet Singh, the South Asia Foundation and the University of Moratuwa, enabling this study which was carried out as part of the requirement for a Master Degree completed at Department of Civil Engineering of University of Moratuwa, Sri Lanka, is gratefully acknowledged. Director General of Irrigation and the staff of Department of Irrigation, Sri Lanka, are appreciated for the opportunity granted and the support extended to carry out this research and associated studies.

\section{References}

1. Bashar, K. E. \& Zaki, A. F. (2005), “SMA Based Continuous Hydrologic Simulation of the Blue Nile", Proceedings International Conference of UNESCO Flanders FUST FRIEND/NILE Project" Towards a Better Cooperation". Sharm El-Sheikh, Egypt.

2. Chow, V. T., Maidment, D. R. \& Mays, L. W. (2010). Applied Hydrology. Tata MacGraw Hill, New Delhi, India.

3. Chow, V. T., Maidment, D. R. \& Mays, L. W. (1988). Applied Hydrology. McGraw- Hill, New York.

4. Cunderlik, J., \& Simonovic, S. P. (2004). "Calibration, Verification and Sensitivity Analysis of the HEC-HMS Hydrologic Model", Department of Civil and Environmental Engineering, The University of Western Ontario.

5. El-Kafagee, M. \& Rahman, A. (2011). 19th International Congress on Modeling and Simulation, Perth, Australia, 12-16 December 2011.

6. Giang, N. T., \& Phuong, T. A. (2010). Calibration and Verification of a Hydrological Model using Event Data. VNU Journal of Science, Earth Sciences, (26), 64-74.

7. Green, I. R. A. \& Stephenson, D. (2009). Criteria for Comparison of Single Event Models. Journal of Hydrological Sciences, 31(3), pp. 395-411.

8. Halwatura, D. \& Najim, M. M. M. (2013). Application of the HEC HMS Model for Runoff Simulation in a Tropical Catchment. Environmental Modelling E Software, 46(2013), pp.155-162.

9. Hearn, D. (2007). A Municipal Guide to the Development of a Watershed Management Plan. Newfoundland and Labrador-Water Resources Management Division, Department of Environment and Conservation: Corner Brook, NL, Canada.

10. Kanchanamala, D. P. H. M., Herath, H. M. H. K. \& Nandalal K. D. W. (2016). Impact of Catchment Scale of Rainfall Runoff Modelling : Kalu Ganga River Catchment upto Ratnapura. Engineer, Vol (XLIX), No.02, pp.1-7. 
11. Lund, Jay R.; Scheierling, Susanne M.; Milne, G.rant. 2010. Modeling for Watershed Management : A Practitioner's Guide. Water Working Notes; No. 27. World Bank, Washington, DC. (c) World Bank. https:/ / openknowledge.worldbank.org/handl e/10986/27841 License: CC BY 3.0 IGO.

12. Madsen, H. (2000). Automatic Calibration of a Conceptual Rainfall-Runoff Model using Multiple Objectives. Journal of Hydrology, 235, pp. 276-288.

13. Manchanayake, P., Sumanaweera, S., \& Jayaratne, J. A. (1985). Some Preliminary Studies on Loss Rates of Few Sri Lankan Catchments. Engineers, Vol (XIII), No.02, 7-12.

14. McEnroe, B. M. (2010). Guidelines for Continuous Simulation of Streamflow in Johnson County, Kansas with HEC-HMS. Johnson County Public works and Infrastructure stormwater Management Programme.

15. Nandalal, H. K. \& Ratnayake, U. R. (2010). Event based Modeling of a Watershed using HEC HMS. Engineer, 43(2), pp. 28-37.

16. Pechlivanidis I. G., Jackson, B. M., Mcintyre, N. R. \& Wheater, H. S. (2001). Catchment Scale Hydrological Modeling : A Review of Model Types, Calibration Approaches and Uncertainty Analysis Methods in the Context of Recent Developments in Technology and Applications. Journal of Global NEST, 13(3), pp. 193-214.

17. Skahill, B. E. (2006). Potential Improvements for HEC HMS Automated Parameter Estimation. Coastal and Hydraulics Laboratory, Engineering Research and Development Centre, U.S. Army Corps of Engineers.

18. United States Army Corps of Engineers, Hydrologic Engineering Centre (USACE 2000), Technical Reference Manual, Davis, California.

19. United States Army Corps of Engineers, Hydrologic Engineering Centre (USACE 1998), User's Manual, Davis, California.

20. USDA-NRCS. (2004). Chapter 9: Hydrologic Soil-Cover Complexes. NRCS National Engineering Handbook, Part 630: Hydrology.

21. United States Army Corps of Engineers, Hydrologic Engineering Centre (USACE 2008) Hydrologic Modeling System HEC-HMS, Applications Guide. US Army Corps of
Engineers, Hydrologic Engineering Center, Washington, DC.

22. United States Army Corps of Engineers, Hydrologic Engineering Centre (USACE 2018) Hydrologic Modeling System HEC-HMS, Release Notes, Version 4.3. US Army Corps of Engineers, hydrologic engineering center, Washington,DC.

23. Ward and Elliot 2004 Environmental Hydrology, Second Edition, Edited by Andy D. Ward, William J. Elliot, ISBN 1-56670-616-5, Lewis Publishers, 2004.

24. Wijesekera, N. T. S. \& Musiake, (1990a). Streamflow Modeling of Sri Lankan catchments (1)- Mahaweli River catchment at Peradeniya, Seisan-Kenkyu, Journal of the Institute of Industrial Science, University of Tokyo,Japan, 42(11), November 1990.

25. Wijesekera, N. T .S. \& Musiake, (1990b). Streamflow Modeling of Sri Lankan catchments(2)- Kalu River catchment at Putupaula, Seisan-Kenkyu, Journal of the Institute of Industrial Science, University of Tokyo, Japan, 42(11), November 1999.

26. Wijesekera, N. T. S.(2010). Surface Water Resources and Climate Change. Proceedings of the National Forum on Water Research "Identification of Gaps and Priorities". National Science Foundation, Sri Lanka.

27. World Meteorological Organization. (1975). Intercomparison of conceptual models used in operational hydrological forecasting. (Operational hydrology report no.7/WMO-No 429). Geneva, Switzerland.

28. Wu, C. L., Chau, K. W. \& Fan, C. (2010). Prediction of Rainfall Time Series using Modular Artificial Neural Networks Coupled with Data-Preprocessing Techniques. Journal of Hydrology, 389(1-2), pp. 146-167.

29. Xuefeng Chu, A. M. ASCE and Steinman, A. (2009). Event and Continuous Hydrologic modeling with HEC HMS. Journal of Irrigation and Drainage Engineering, ASCE.

30. Zhang, Y., Vaze, J., Franncis, H. S., Chiew \& Li M. (2015). Comparing Flow duration Curve and Rainfall - Runoff Modelling for Predicting Daily Runoff in Ungauged Catchments. Journal of Hydrology, 525. pp.72-86. 